\title{
Penciptaan Karya Film Animasi 2D \\ "Miliv" Dengan Teknik Hybrid
}

\author{
Rafinur Nidiansyah ${ }^{1}$, \\ Arif Sulistiyono ${ }^{2}$, Pandan Pareanom $\mathbf{P}^{3}$ \\ Program Studi Animasi, ISI Yogyakarta
}

Email: rafnarog@gmail.com ${ }^{1}$, arifgokong@gmail.com ${ }^{2}$,pianisganteng@yahoo.com³

\begin{abstract}
Abstrak
Ketika manusia menyadari bahwa dirinya tidak seperti yang terlihat, hal itu menyebabkan konflik pribadi pada manusia, ada dua sumber yang berasal dari dalam dan luar. Dengan film animasi yang sudah semakin banyak diminati berbagai kalangan, diciptakannya film animasi "MILIV" sebagai salah satu media penyampaian dalam bentuk visual dan media penyampaian pesan yang terdapat pada film.

Dengan konsep hybrid yaitu mengkombinasikan teknik animasi stopmotion, rotoscope, dan animasi digital, menciptakan sebuah karya animasi bergenre eksperimental dengan gaya visual yang unik nantinya.

Karya film animasi "MILIV" menceritakan seekor burung yang terlambat menyadari jati dirinya dan terjebak di dalam zona nyaman. Berkontemplasi menjadi tujuan utama dalam film animasi "MILIV" ini.

Kata kunci : Film, MILIV, Hybrid, Rotoscope, Stopmotion, Eksperimental, Animasi

Abstract

When human realize that they are not as they appear, it causes personal conflicts in humans, there are two sources that come from inside and outside. With animated films that have become increasingly popular with various groups, the creation of the animated film "MILIV" as one of media delivery in the form of visual and media delivery messages contained in the film.

With the concept of hybrid, it combines stopmotion animation techniques, rotoscope, and digital animation, creating an experimental genre animation work with its unique visual style.

The animated film "MILIV" tells of a bird who is too late to realize his true identity and is trapped in comfort zone. Contemplation became the main goal in this animated film "MILIV"
\end{abstract}

Keywords: Film, MILIV, Hybrid, Rotoscope, Stopmotion, Experimental, Animation 


\section{LATAR BELAKANG}

Berdasarkan Risalah Ath-Thair karya Ibnu Sina yang mengemukakan bahwa manusia itu diibaratkan sebagai burung dalam sangkar. Burung dalam sangkar sendiri memiliki filosofi suatu bentuk ketidakpuasan manusia akan terbatasnya kehidupan dirinya selama di dunia, padahal keterbatasanya tersebut hanya terdapat dalam imajinasinya saja. Pada kenyataannya yang membuat kehidupan seseorang terbatas itu ialah dirinya sendiri bukan orang lain.

Berdasarkan filosofi tersebut tercetuslah ide untuk membuat film ini. Dengan burung sebagai karakter utama mewakilkan seorang manusia yang terbelenggu dalam zona nyamannya dan beranggapan bahwa di dalam sangkar ialah tempat yang terbaik, hal ini yang menjadikan salah satu bentuk keresahan yang banyak digambarkan oleh masyarakat saat ini.

Perkembangan zaman yang semakin modern menjadikan teknik pembuatan animasi semakin beragam diantaranya teknik rotoscope, stopmotion, animasi digital. Dikutip dari salah satu sineas Yogyakarta, Senoaji Julius, "film eksperimental bisa dibilang adalah suatu bentuk usaha seniman dengan mencoba memasukan hal baru yang belum pernah dicoba pada karya-karya sebelumnya demi menghasilkan suatu karya yang inovatif."

Hal iniyangmendasariterciptanyakarya film animasi“MILIV" denganmenggunakan salah satu genre yang membebaskan film maker sebagai media untuk mengekspresikan diri akan sebuah pemikiran atas dasar konsep yang telah dibuat sebelumnya. Dengan menggabungkan berbagai teknik penganimasian seperti rotoscope yang menimbulkan bentuk realistis sebuah karakter, stopmotion yang memberikan gerakan patah-patah, dan digital cut out yang memberikan sensasi gerakan wayang yang dipadukan sedemikian rupa menjadikan salah satu hal yang menarik dalam proses pembuatannya.

\section{RUMUSAN MASALAH}

Berdasarkan latar belakang di atas dapat dirumuskan permasalahan yang akan diselesaikan yaitu menciptakan animasi eksperimental 2D "MILIV" menjadi satu film yang utuh.

\section{TUJUAN}




\section{Rafinur Nidiansyah, Arif Sulistiyono, Pandan Pareanom P}

Penciptaan Karya Film Animasi 2D "Miliv" Dengan Teknik Hybrid

Tujuan dari penciptaan karya film animasi 2D "MILIV" antara lain :

1. Harapannya dapat menjadi bahan instropeksi diri agar setiap orang sadar bagaimana cara mensyukuri hidup dan dapat merenungi setiap kesalahan yang dibuat.

2. Bahan pengajuan ke festival film animasi baik nasional maupun internasional.

3. Menciptakan karya film animasi eksperimental dengan teknik hybrid3

\section{TARGET AUDIEN}

Target audien penciptaan karya film animasi 2D "MILIV" ini adalah:
1. Usia
: 18 tahun ke atas
2. Jenis kelamin : Laki-laki dan perempuan
3. Status sosial : Semua kalangan
4. Negara : Global

\section{INDIKATOR CAPAIAN AKHIR}

Capaian akhir dari film "MILIV" yaitu apabila telah melalui tahapan-tahapan produksi, sehingga menjadi satu film animasi yang utuh. Total durasi 3 menit 42 detik dengan jumlah 5327 frame : 24 frame per second sudah termasuk bumper opening dan credit title, dengan tahapan sebagai berikut:

\section{Praproduksi}

Praproduksi adalah tahap persiapan atau proses sebelum masuk ke dalam tahapan produksi animasi

\section{a. Penulisan Cerita}

Proses dimana dibangunnya sebuah ide cerita melalui brainstorming agar menjadi pondasi dalam pembuatan sebuah film.

\section{b. Research Data}

Informasi yang telah dikumpulkan dan diamati yang hasilnya digunakan untuk sebuah penelitian.

\section{c. Design character}


Salah satu bentuk konsep ilustrasi dengan segala atribut baik sifat, fisik, maupun takdir, dapat berupa hewan, tumbuhan atau manusia. Yang nantinya digunakan sebagai model sheet dalam proses animating.

\section{d. Sinopsis}

Pembuatan garis besar suatu cerita yang nantinya dikembangkan menjadi sebuah skenario yang di dalamanya terdapat sebuah infomasi tentang alur dan gambaran cerita nantinya.

\section{e. Skenario}

Tahap lanjutan dari sebuah synopsis yang di dalamnya memuat cerita yang lengkap yang kemudian dijabarkan menjadi pembagian scene, babak, dan deskripsi. Yang nantinya menjadi bahan acuan pembuatan storyboard.

\section{f. Storyboard}

Gambaran tampilan animasi yang di dalamnya terdapat deskripsi, pengambilan angle kamera yang dibuat sesuai dengan skenario.

\section{g. Stillomatic}

Merupakan penggabungan urutan adegan gambar menjadi sebuah video, yang ditunjukan untuk memperjelas tampilan karya animasi. Dengan disusun menjadi satu sehingga dapat mempermudah animator dalam proses animating.

\section{Produksi}

Produksi adalah proses inti penciptaan animasi, proses ini dilakukan setelah tahap praproduksi selesai.

\section{a. Live Shoot}

Proses merekam adegan dalam film sesuai dengan naskah yang terdapat dalam storyboard. Lokasi shooting dapat berada dalam ruangan maupun luar ruangan.

\section{b. Offline Editing}




\section{Rafinur Nidiansyah, Arif Sulistiyono, Pandan Pareanom P}

Penciptaan Karya Film Animasi 2D "Miliv" Dengan Teknik Hybrid

Hasil rekaman video kemudian dipilih dan diubah kedalam bentuk image-sequence dan disesuaikan dengan keterangan scene dan shot.

\section{c. Rotoscope}

Proses penjiplakan gambar atau tracing yang dilakukan setelah image- sequence disusun. Dengan menggambar pada layer baru disetiap image-sequence, sesuai gerakan dan dirubah sedikit jadi tidak hanya menjiplak gambar.

\section{d. Animating Stopmotion}

Proses pembuatan animasi dengan menjadikan sebuah karakter, yang nantinya difoto frame by frame menggunakan kamera still yang kemudian diedit menjadi gambar yang tersusun dan disesuaikan lagi timing penganimasiannya.

\section{e. Background}

Tempat yang ditampilkan dalam cerita yang di dalamnya memberikan batasan suatu peristiwa.

\section{f. Animating}

Proses menggerakan karakter dan background serta penambahan visual effect agar animasi menjadi semakin menarik.

\section{g. Compositing}

Penggabungan antara background dan animasi yang disesuaikan dengan durasi dan berbagai penambahan visual effect yang memberikan kesan unik dan menarik.

\section{h. Music}

Dengan menambahkan music scoring yang menjadi original soundtrack yang telah disesuaikan dengan bentuk visual film animasi.

\section{PascaProduksi}


Pascaproduksi adalah tahapan akhir atau proses penyelesaian.

\section{a. Editing dan Rendering}

Proses dimana video dan audio serta penambahan transisi, judul dan efek yang digabung menjadi satu dan disunting kembali dengan memotong klip video atau audio yang dianggap kurang sesuai.

\section{b. Render and Mastering}

Tahap terakhir karya yang sudah selesai dibuat dengan meng-export file menjadi satu film yang utuh ke dalam format .mp4. yang kemudian di burning menjadi piringan DVD, lalu di masukan ke dalam case DVD dan diberi sampul.

\section{c. Display dan Merchandising}

Display karya akan dilakukan selepas karya selesai dibuat.

\section{LANDASAN TEORI}

Animasi berasal dari kata "to animate" yang berarti seolah hidup atau bergerak. Animasi 2D merupakan sebuah teknik pembuatan animasi dengan menggunakan gambar bersumbu yaitu $\mathrm{X}$ dan $\mathrm{Y}$, namun lebih dikenal dengan animasi manual karena proses pembuatannya, Bambi Bambang Gunawan (Nganimasi Bersama Mas Be, 2013:27).

Secara etimologis hybrid adalah penggabungan dua unsur yang berlawanan (binari oposisi) namun tetap mempertahankan masing-masing karakter dari unsur tersebut, dalam pengertian hybrid terbagi atas persilangan, percampuran, dan penggabungan. Lalu menurut M.S. Gumelar dalam bukunya 2D Animation,

Hybrid Technique, Teknik Animasi 2D Hybrid yaitu menggabungkan antara cara tradisional dan cara digital, beberapa jumlah dan persentase digital dan tradisionalnya tidak begitu dipermasalahkan yang penting menggabungkan dua cara tersebut.

Dalam penciptaan karya film animasi "MILIV" yang menggunakan konsep hybrid dalam pembuatannya yaitu mengkombinasikan tiga teknik animasi digital cut out, rotoscope, dan stopmotion. Menurut Margery Brown dalam bukunya 


\section{Rafinur Nidiansyah, Arif Sulistiyono, Pandan Pareanom P}

Penciptaan Karya Film Animasi 2D "Miliv" Dengan Teknik Hybrid

Experimental Animation Techniques, animasi cut out adalah teknik membuat animasi dengan menggunakan suatu bidang datar untuk tiap karakter, property, ataupun background. Yaitu dengan menyusun kemudian menggerakan potongan kertas atau sejenisnya hingga tercipta suatu gerakan.6

Mengutip dari Buku Pengantar Animasi 2D: Metode Dasar Perancangan Animasi Tradisional karya A.A. Suwasono, menjelaskan bahwa animasi stopmotion adalah sebuah teknik animasi yang dapat membuat benda diam akan terlihat bergerak. Lalu Gatot Prakosa menuturkan di dalam bukunya yang berjudul Animasi (2010:249-250) bahwa rotoscope merupakan produksi film animasi yang memerlukan sebuah model agar bisa mendapatkan gerakan pemain dengan bagus dan menarik. Dengan melakukan pengambilan gambar secara langsung untuk kemudian dijadikan image-sequence lalu dilakukan proses tracing atau menjiplak. Teknik ini menghasilkan gaya visual yang realis karena gambar merupakan hasil dari perekaman adegan secara langsung.

Pengertian filsafat islam berdasarkan kutipan dari buku Filsafat Islam: Sebuah Kajian Tematik, (Dr. Zaprulkhan, 2014:3) yaitu :

Filsafat Islam ialah gabungan dari dua kata, yaitu filsafat dan islam. Secara etimologi, filsafat berasal dari Bahasa Yunani yaitu kata philein atau philos dan shopia. Kata philein atau philos berarti cinta, tapi dalam makna yang luas yakni berupa hasrat ingin tahu seseorang terhadap kebijaksanaan, ilmu pengetahuan atau kebenaran. Sedangkan kata shopia berarti kebijaksanaan. Sehingga secara sederhana, filsafat adalah mencintai kebijaksanaan.

Ibnu Sina merupakan tokoh pemikir islam dimana karya esainya yang berjudul Risalah Ath-Thair (risalah burung) yang di dalamnya menceritakan sekawanan burung dari langit yang mengemban tugas di bumi. Tetapi tidak semulus dan semudah yang mereka bayangkan. Ketika sampai di bumi mereka terkurung dalam sebuah sangkar tubuh, hingga melupakan jati dirinya sebagai burung dan melupakan tugas dan amanah yang mereka emban. Fariduddin Attar juga menjelaskan makna burung dalam bukunya yang berjudul Manthiq At-Thair atau musyawarah burung. Burung adalah binatang yang pintar, bahkan lebih dari sekedar kepintaran kognitif, mereka juga memiliki kepintaran empatis, yang artinya selain melambangkan ruh, burung juga melambangkan akal.

Dalam pembuatan animasi 2D "MILIV" menerapkan beberapa prinsip animasi yang dikenalkan oleh animator Disney, Ollie Johnson dan Frank Thomas dalam bukunya The 
Book Of Life: Disney Animation, berikut beberapa prinsip animasi yang diterapkan, meliputi Anticipation, Staging, Solid Drawing, Slow In Slow Out, Arcs, Timing And Spacing, Secondary Action, Squash And Stretch, Exaggeration, Appeal.

\section{TINJAUAN KARYA}

\section{See Saw}

See saw merupakan sebuah film animasi karya Case Jenigan dan Erik Winkowski yang berdurasi 2 menit 15 detik. Animasi ini memiliki konsep visual yang unik dan cenderung berbeda dari yang lain. Dengan genre eksperimental menjadikan film ini sebagai referensi dalam background dan gaya visual animasi MILIV.

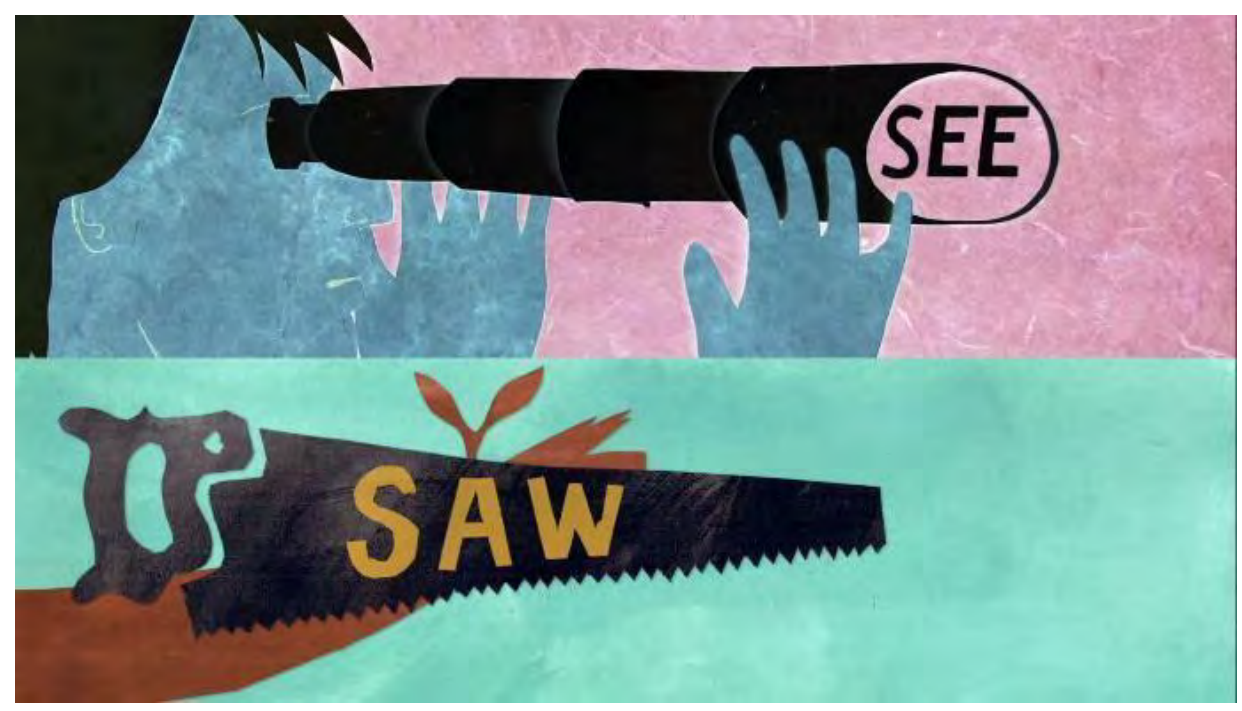

Gambar 1. Film See Saw

\section{Zombie Boyfriend}

Zombie Boyfriend adalah karya animasi dari Case Jernigan yang menceritakan seorang kekasih wanita yang memberanikan diri untuk melawan zombie yaitu kekasih prianya sendiri. Film ini menjadi referensi dari segi visual dan teknik pembuatan yang yang menggunakan teknik cut out digital dan stopmotion. 
Rafinur Nidiansyah, Arif Sulistiyono, Pandan Pareanom P

Penciptaan Karya Film Animasi 2D "Miliv" Dengan Teknik Hybrid

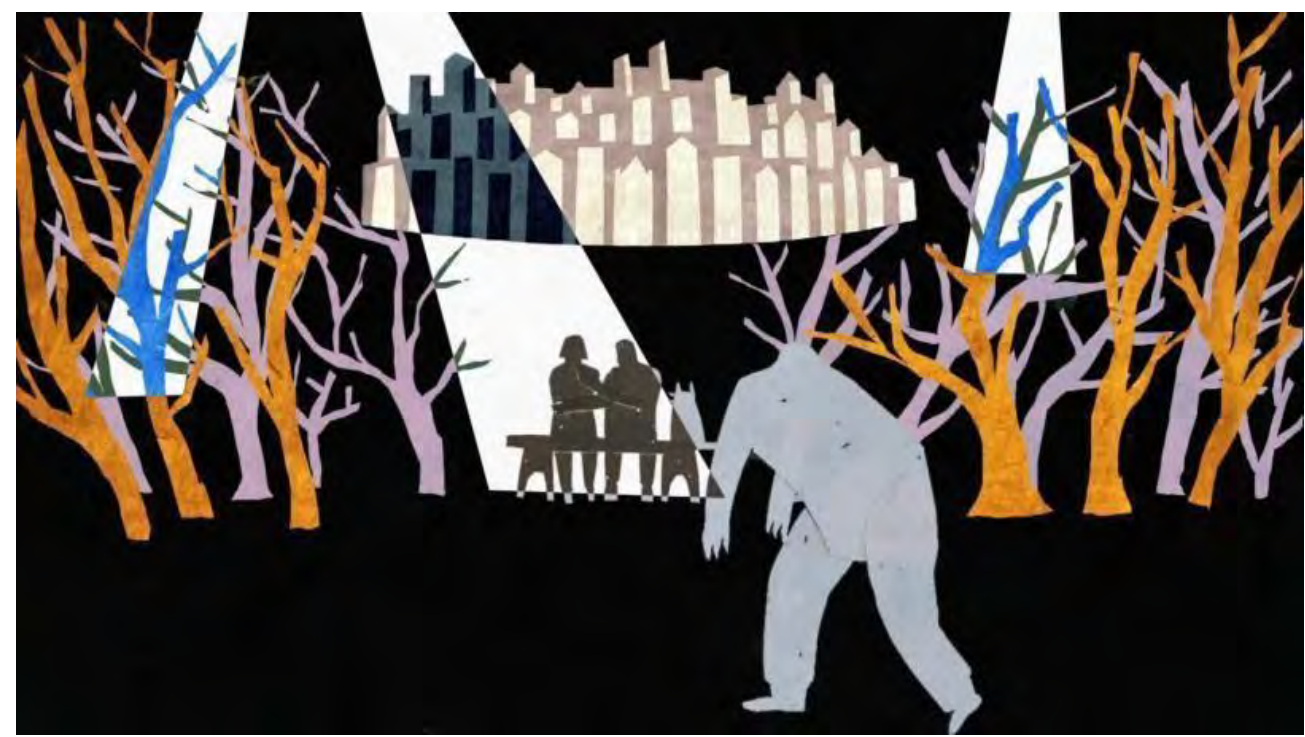

Gambar 2. Film Zombie Boyfriend

\section{Video music animasi Jevin Julian ft. A. Nayaka - Capone}

Video musik animasi ini adalah sebuah video musik arahan dari sutradara Wiradhamsa dan diproduseri oleh GVNGGIF, dimana video ini juga memiliki visual yang unik dan efek visual yang banyak menjadikan tinjuan karya dalam pembuatan animasi "MILIV".

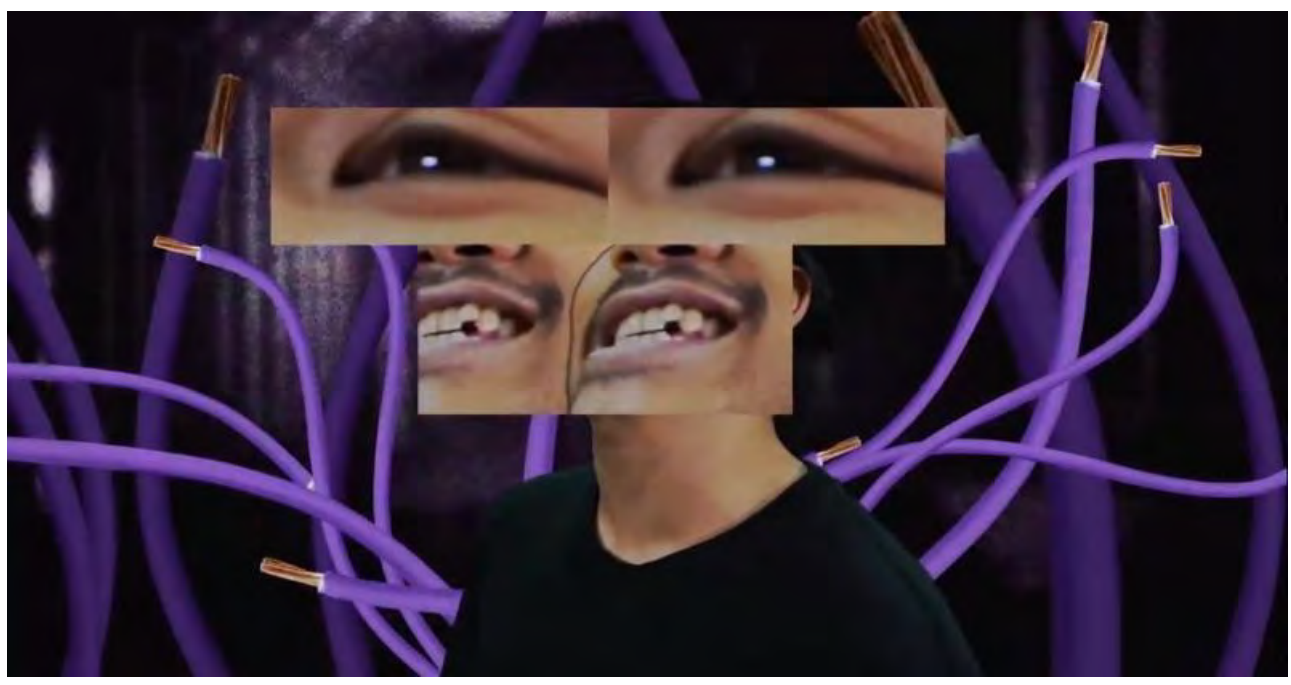

Gambar 3. Video music Jevin Julian - Capone 


\section{Noch Am Leben}

Noch Am Leben adalah film animasi garapan Anita Lester yang merupakan salah satu peserta dalam International Jewish Film Festival yang filmnya sebagian besar menggunakan teknik rotoscoping. Dari film ini menjadikan salah satu tinjuan karya dalam pembuatan film animasi "MILIV" dengan teknik rotoscope.

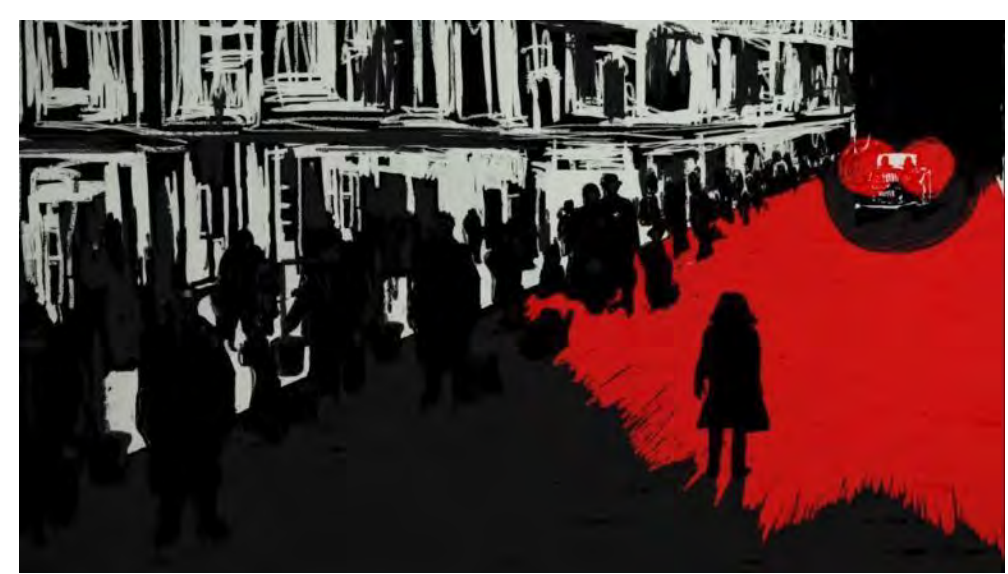

Gambar 4. Film Noch Am Leben

\section{Lukisan Pablo Picasso - Three Musicians}

Lukisan karya Pablo Picasso ini merupakan lukisan minyak di atas kanvas dan termasuk kedalam lukisan yang beraliran kubisme. Lukisan ini dibuat tahun $1921 \mathrm{M}$ di Perancis, dan sekarang ada di dalam Museum of Modern Art di kota New York, Amerika Serikat. Lukisan ini menjadikan salah satu acuan dalam pembuatan karakter film animasi "MILIV" dengan gaya aliran kubisme.

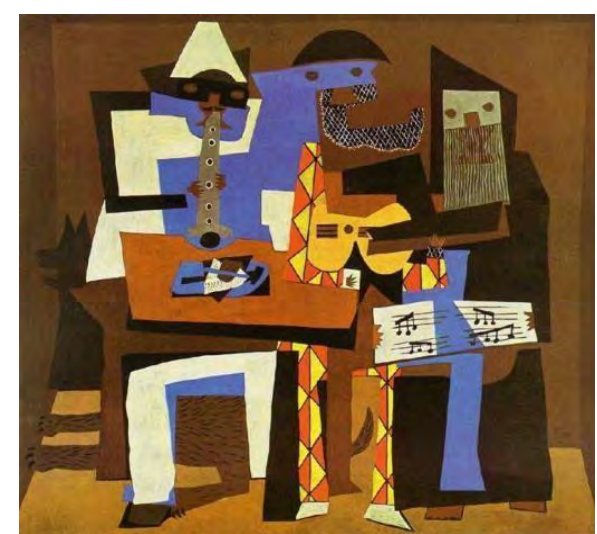


Rafinur Nidiansyah, Arif Sulistiyono, Pandan Pareanom P

Penciptaan Karya Film Animasi 2D "Miliv" Dengan Teknik Hybrid

\section{CERITA}

\section{Sinopsis}

Seekor burung yang lahir ke dunia dan terbang untuk sebuah tujuan, tetapi ditengah perjalanan burung tersebut tertangkap oleh pemburu, kemudian dia dimasukan ke dalam sangkar dengan segala kemudahan. Hingga akhirnya burung tersebut melupakan jati diri serta melupakan apa yang menjadi tujuannya. Sampai suatu ketika dia tersadar, namun semuanya terlambat dan burung itu mati dengan kesia-siaan.

\section{Treatment}

\begin{tabular}{|c|c|c|}
\hline Sequence & Pokok Materi & Durasi \\
\hline SC. 01 - EXT. & $\begin{array}{l}\text { Terlihat gundukan tanah lalu muncul } \\
\text { burung dari dalamnya, burung itu } \\
\text { kemudian bersiap untuk terbang. } \\
\text { Muncul Judul film "MILIV" }\end{array}$ & 11 detik \\
\hline SC. 02-EXT. & $\begin{array}{l}\text { Dia terbang diatas gedung-gedung } \\
\text { melewati kota menuju hutan. }\end{array}$ & 15 detik \\
\hline SC. 03 - EXT. & $\begin{array}{l}\text { Ketika sedang asik terbang beberapa } \\
\text { burung ikut terbang disampingnya. } \\
\text { Kemudian beberapa tank muncul dengan } \\
\text { menembakkan jaring penangkap ke arah } \\
\text { burung dan mengenani burung tersebut. }\end{array}$ & 9 detik \\
\hline SC. 04 INT. & $\begin{array}{l}\text { Jaring itu kemudian berubah mengurung } \\
\text { badan si burung. Karena takut lalu dia } \\
\text { berteriak. Tiba-tiba datang sebuah tangan } \\
\text { membawa makanan dan menjejalkan } \\
\text { makanan tersebut ke dalam mulut. Hingga }\end{array}$ & 29 detik \\
\hline & $\begin{array}{l}\text { burung merasa terhipnotis oleh makanan } \\
\text { itu. }\end{array}$ & \\
\hline SC. 05 INT. & $\begin{array}{l}\text { Tangan yang mengunyah makanan } \\
\text { dengan rakus. }\end{array}$ & 2 detik \\
\hline SC. 06 INT. & Mulut yang mengunyah-ngunyah. & 3 detik \\
\hline SC. 07 INT. & $\begin{array}{l}\text { Tangan mengunyah makanan dengan } \\
\text { rakus. }\end{array}$ & 2 detik \\
\hline SC. 8 INT. & Burung meminum air. & 4 detik \\
\hline SC. 9 INT. & Burung memakan makanan. & 2 detik \\
\hline
\end{tabular}




\begin{tabular}{|c|c|c|}
\hline SC. 10 INT. & Burung tertidur. & 2 detik \\
\hline SC.11 INT. & Balon yang dipompa sampai meledak. & 12 detik \\
\hline SC. 10 SH. 2 INT. & Burung terbangun dan membuka mata. & 2 detik \\
\hline SC. 12 INT. & $\begin{array}{l}\text { Burung diberi makan dan membuang } \\
\text { makanannya. Lalu karena merasa kesal } \\
\text { dia berteriak dan berputar-putar hingga } \\
\text { burung berhalusinasi. }\end{array}$ & 12 detik \\
\hline SC.13 INT. & $\begin{array}{l}\text { Halusinasi burung yang terbang melewati } \\
\text { pohon-pohon dijalanan. }\end{array}$ & 12 detik \\
\hline SC.14 INT. & $\begin{array}{l}\text { Terlihat sesosok manusia yang sedang } \\
\text { depresi. }\end{array}$ & 9 detik \\
\hline SC.15 INT. & $\begin{array}{l}\text { Burung tersebut merasa pusing sampai } \\
\text { akhirnya terjatuh dan terbukalah sangkar } \\
\text { yang mengurung badan burung. }\end{array}$ & 9 detik \\
\hline \multirow[t]{3}{*}{ SC.16 INT. } & $\begin{array}{l}\text { Muncul sepasang tangan yang datang } \\
\text { meraup burung, dan digenggamnya } \\
\text { menuju pintu keluar lantas mengubur } \\
\text { burung tersebut. Tak lama setelah } \\
\text { ditinggal keluarlah ruh burung itu dari } \\
\text { makamnya, }\end{array}$ & 36 detik \\
\hline & QUOTES & 10 detik \\
\hline & Credit Tittle & 26 detik \\
\hline
\end{tabular}

\section{DESAIN KARAKTER}

\section{Burung}

Desain burung dengan menggabungkan bentuk-bentuk geometris dan warna yang memiliki makna disetiap bagiannya. Berikut penjelasan wataknya :

Warna merah pada kepala digambarkan sebagai orang yang berani dan menarik perhatian. Warna jingga pada leher digambarkan sebagai orang yang selalu ceria dalam berbagai hal. Warna biru pada badan digambarkan sebagai sifat manusia yang kadang membosankan. Hijau pada sayap digambarkan dengan makna kebebasan dan kedamaian. Namun, cenderung tidak memiliki arah tujuan yang jelas. Hitam pada paruh digambarkan sebagai seorang yang kuat dan rakus. Serta bentuk mata digambarkan sebagai manusia itu sendiri. Sedangkan bentuk lingkaran melambangkan kesatuan, kotak atau persegi panjang melambangkan kesetaraan dan bentuk segitiga melambangkan pengenalan diri. 
Rafinur Nidiansyah, Arif Sulistiyono, Pandan Pareanom P

Penciptaan Karya Film Animasi 2D "Miliv" Dengan Teknik Hybrid

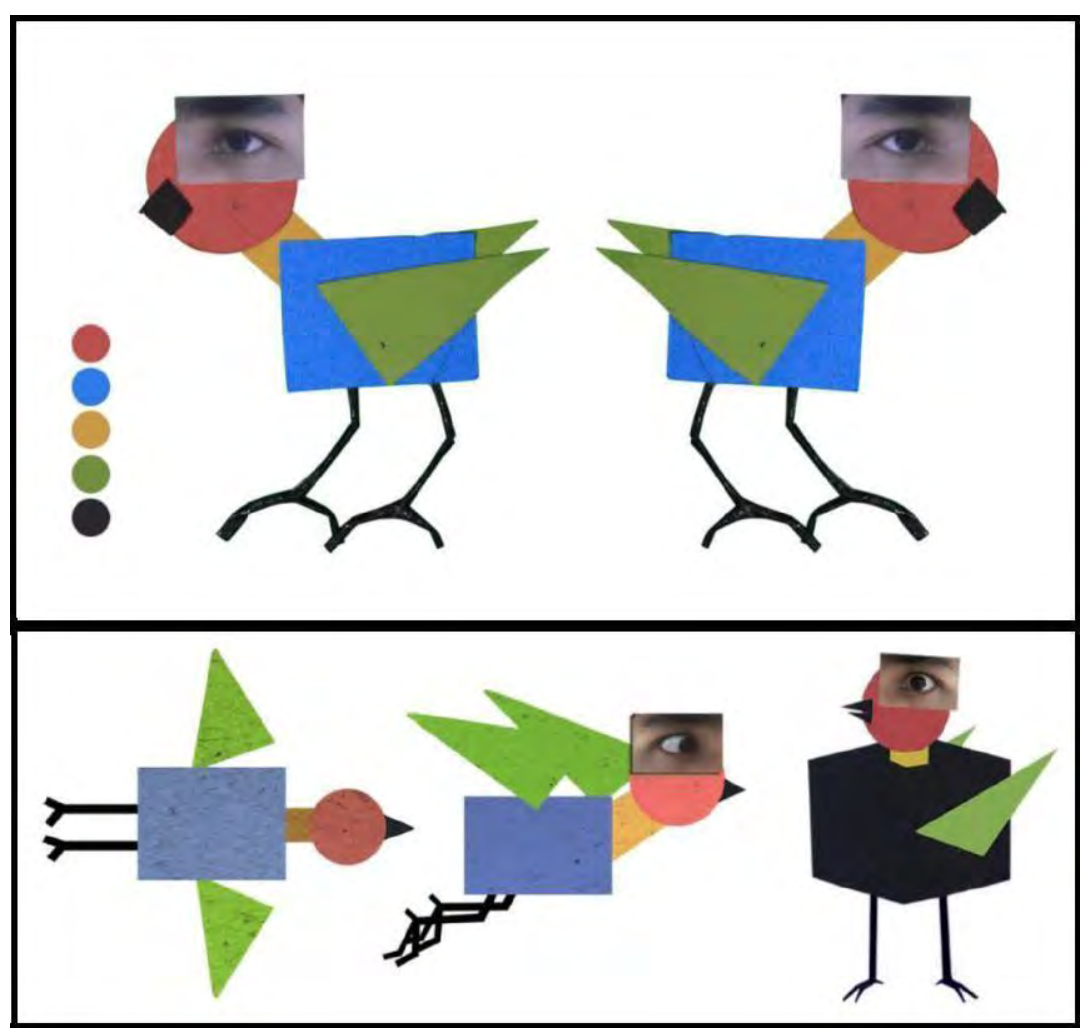

Gambar 6. Karakter Burung

\section{Karakter Tangan}

Karakter ini cukup berperan penting dalam beberapa adegan, Yang digambarkan sebagai sesosok yang memanjakan dan pengayom, dan juga sebagai tokoh tritagonis.

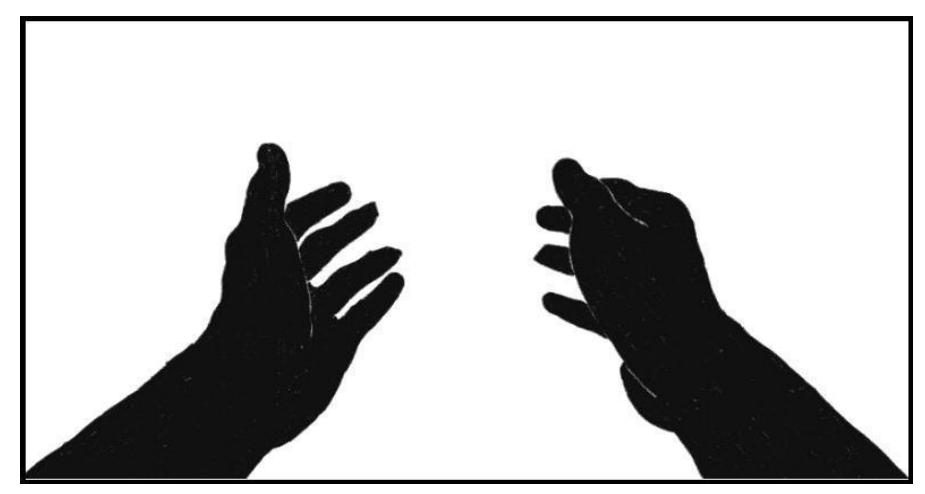

Gambar 7. Karakter Tangan

\section{Karakter Figuran}


Karakter yang dibuat sebagai selingan dalam beberapa scene juga sebagai pembeda dari karakter utama.

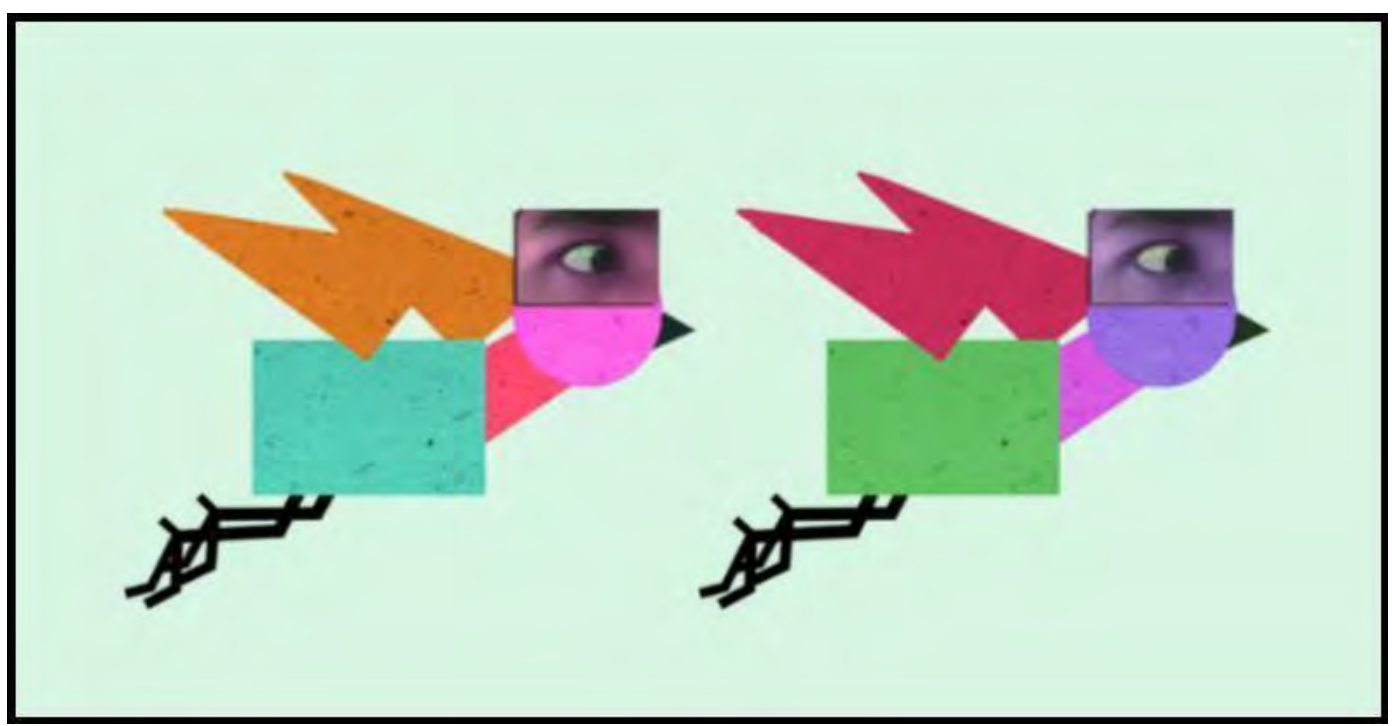

Gambar 8. Karakter Figuran

\section{SOFTWARE}

Software yang digunakan adalah :

Adobe Photoshop CS6

Dragonframe 4

Adobe After Effect CS6

Logic Pro X

Adobe Premiere Pro CS6

\section{BACKGROUND MUSIC}

Musik pada film animasi "MILIV" merupakan musik scoring yang dikerjakan oleh seorang composer dengan menggunakan software Logic Pro $X$ yang durasinya mengacu pada film, music scoring dipilih sebagai pengatur mood pada jalan cerita film. Dan instrument yang digunakan meliputi drum, organ, synthesizer, guitar, piano, mallet, percussion.

\section{KONSEP DASAR}




\section{Rafinur Nidiansyah, Arif Sulistiyono, Pandan Pareanom P}

Penciptaan Karya Film Animasi 2D "Miliv" Dengan Teknik Hybrid

Konsep dasar dari animasi "MILIV" yaitu berawal dari sebuah keresahan seorang teman yang mengalami masalah pada dirinya, baik itu dari keluarga maupun lingkungan pendidikan yang memaksa meraka untuk selalu mengikuti aturan yang berlaku. Kemudian dengan mengumpulkan sejumlah data dan pematangan konsep dibuatlah sebuah premis cerita yang menjadikan ide awal konsep sebuah film animasi, yang memuat berbagai simbol-simbol yang mempunyai makna didalamnya.

Tema dalam film animasi "MILIV" adalah tentang sebuah masalah internal yang sering dijumpai oleh manusia di lingkungan sekitar.

\section{PEMBAHASAN ISI FILM}

Film animasi 2D "MILIV" ialah film animasi yang di dalamnya mengandung unsur surealis dan simbolik, dan sebuah pesan yang tersirat dari karakter dan setiap adegannya yang kemudian divisualisasikan ke dalam bentuk film animasi. Berikut adalah beberapa shot pembahasan dari film animasi 2D "MILIV" dengan teknik hybrid.

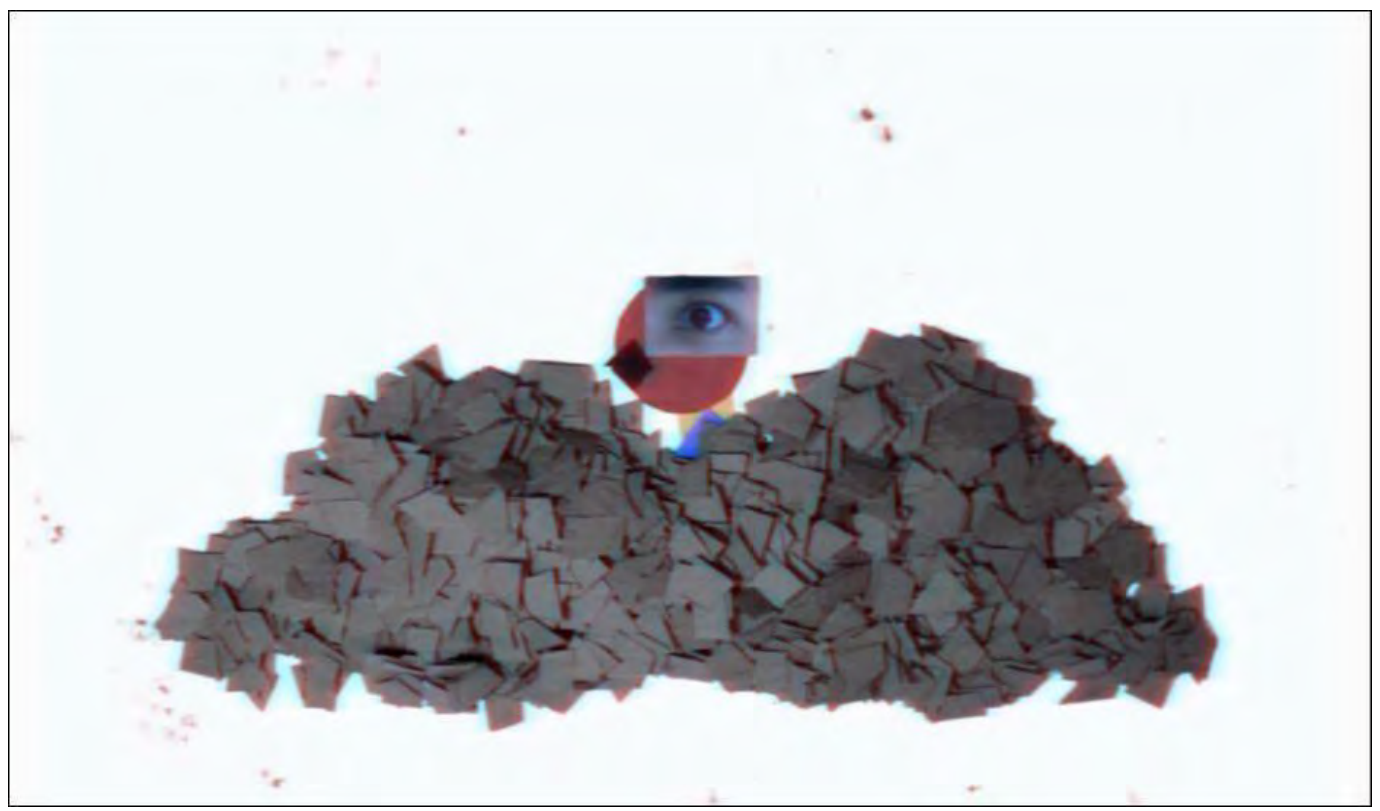

Gambar 9. Scene 01 Shot 01 - 02 film animasi "MILIV"

Awal scene terlihat sebuah gundukan tanah tak lama sesosok burung dari tanah tersebut, yang direpresentasikan sebagai awal dari kelahiran manusia di dunia. 


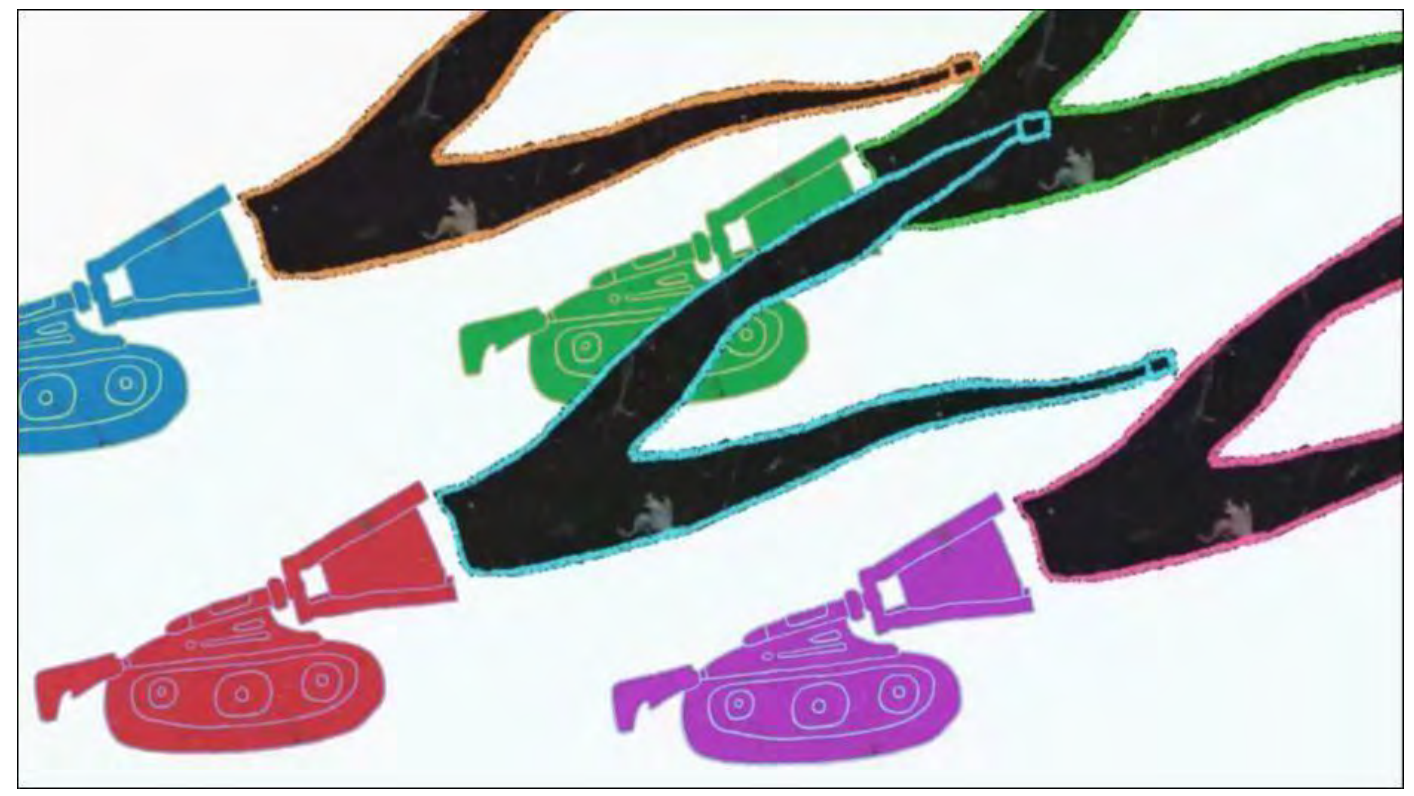

Gambar 10. Scene 03 Shot 02 film animasi "MILIV"

Penggambaran beberapa tank yang muncul tiba-tiba dengan menembakan jaring menjelaskan bahwa sebuah masalah dapat muncul secara tiba-tiba, tank menggambarkan sebuah masalah yang berat dengan perangkap jaring yang memperkuatnya.

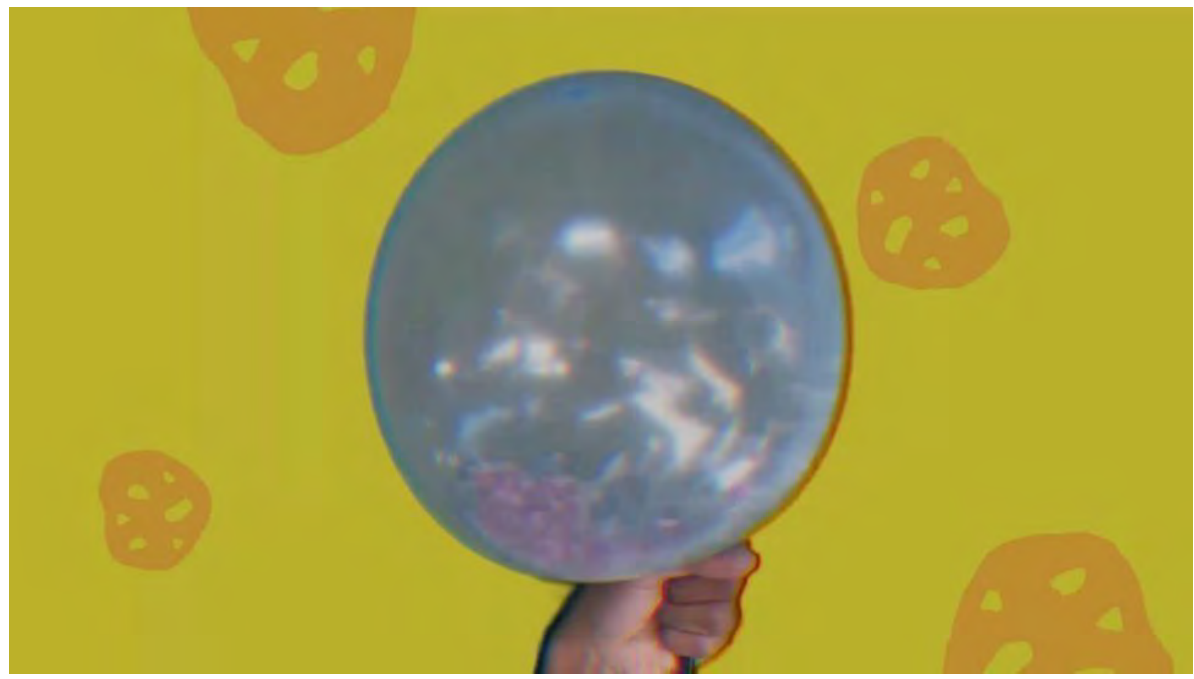

Gambar 11. Scene 11 film animasi "MILIV"

Pada (Gambar 5.18 Scene 11) sebuah balon yang digenggam dan dipompa sampai meletus menjelaskan sebuah titik jenuh dimana perasaan tersebut kerap dirasakan oleh setiap manusia. 


\section{HARGA JUAL ANIMASI}

Pada film animasi "MILIV" penentuan harga jual animasi dihitung berdasarkan durasi yang dibuat, untuk full animasi "MILIV" sendiri berdurasi 3 menit 42 detik dengan frame rate $24 \mathrm{fps}$, maka total keseluruhan animasi "MILIV" jika dihitung framenya dikalikan 24 fps berjumlah sebanyak 5327 frame.

Untuk tiap detiknya dihargai Rp 50.000 , maka harga jual animasi "MILIV" adalah seluruh jumlah detik dikalikan Rp 50.000, maka hasilnya yaitu Rp 11.100.000.

\section{PENUTUP}

Berdasarkan penulisan laporan, berikut adalah kesimpulan yang didapatkan dari seluruh proses Penciptaan Karya Film Animasi 2D "MILIV” dengan teknik hybrid:

1. Penciptaan Film Animasi 2D "MILIV" telah selesai dengan pesan yang ingin disampaikan durasi utuh 3 menit 42 detik.

2. Jumlah Scene mencapai 16 Scene dengan total 5327 frame format HDTV 1920x1080 px 24 fps (frame per second).

3. Penciptaan Film Animasi 2D "MILIV" merupakan film animasi eksperimental dengan menggunakan teknik animasi stopmotion, rotoscope, dan animasi digital.

\section{SARAN}

Berbagai proses dalam Penciptaan Film Animasi 2D "MILIV" telah dilalui, ada beberapa hal yang dapat menjadi saran yang membangun dan bernilai positif antara lain : 1. Buat tujuan yang jelas dalam untuk siapa film itu ditujukan.

2. Perbanyakan referensi buku dan film untuk memantapkan konsep cerita maupun visual.

3. Penguatan konsep yang kuat dan lakukan diskusi dengan mahasiswa dari berbagai jurusan untuk melihat sudut pandang dan berbagai kemungkinan.

4. Maksimal bahan-bahan dalam membuat stopmotion dengan budget yang minim. 
Journal of Animation \& Games Studies, Vol . 5 No. 1 - April 2019

ISSN 2460-5662

5. Dalam membuat rotoscope usahakan jangan menunda-nunda waktu pengerjaan sehingga dapat diselesaikan dengan cepat.

6. Buatlah jadwal yang realistis dan disiplin dalam memenuhi jadwal. 


\section{DAFTAR PUSTAKA}

\section{Buku}

Al-quran, Surat Al-Mulk. 65:15

A. A Suwasono, 2016. Pengantar Animasi 2D (Metode Dasar Perancangan Animasi Tradisional). BP ISI Yogyakarta.

Blazer, Liz. 2016. Animated Storytelling (Simple Steps for Creating Animation Motion Graphics). Peachpit Press. Brown, Margery. Experimental Animation.

Danesi, Marcel, 2014. Messages, Signs, and Meaning: A Basics Textbook in Semiotic and Communication Theory, $3^{\text {rd }}$ edition, Canada: Canadan scholars' Press Inc.

Fariduddin'Attar, 1983. Musyawarah Burung. Terjemah.Hartojo Andangdjaja. Jakarta: Pustaka Jaya

Gumelar, Michael Saga, 2010. 2D Animation: Hybrid Technique. Jakarta: An1mage

Gunawan, Bambi Bambang, 2013. Nganimasi Bersama Mas Be. Yogyakarta: Elex Media Komputindo

Johnston, Ollie., Frank Thomas. 1995. The Illusions of Life Disney Animation. Italy: Disney Productions.

Menache, Menache, 2010. Computer Animation Complete.

Metha, Aline, 2014. The True Color of Power. Yogyakarta: Octopus

Prakosa, Gotot, 2010. Animasi (Pengetahuan dasar film animasi di Indonesia). Jakarta: FFTV-IKJ.

Zaprulkhan, 2014. Filsafat Islam: Kajian Tematik. Jakarta: Rajawali Pers

\section{Laman :}

https://alif.id/read/fuji-nur-iman/fariduddin-attar-dan-mantiqut-thair-cermin-perjalananspiritual-manusia-b210973p/ ( diakses pada 27 Desember 2018, pukul 22.00)

https://beritagar.id/artikel/ramadan/catatan-sufistik-burung-pun-berakal (diakses pada 22 November 2018, pukul 21.00) 
http://berkacakata.blogspot.com/2015/03/memaknai-film-eksperimental.html (diakses pada 22 November 2018, pukul 19.00)

http://celotehcelatah.blogspot.com/2012/12/mengenal-bentuk-geometris-danmaknanya.html (diakses pada 21 Agustus 2018, pukul 13.45)

https://dosenpsikologi.com/4-karakter-manusia (diakses pada 29 November 2018, pukul 11.08)

https://www.kompasiana.com/alimukti37/550d951f8133115d22b1e46f/burung-dimata- filsuf-dan-sufi (diakses pada 27 September 2018, pukul 11.30) https://miklotof.wordpress.com/2010/09/12/manusia-dalam-konsep-filsafat-ibn-sina/ (diakses pada 27 September 2018, pukul 11.30) https://quran.com/67/15 (diakses pada 22 November 2018, pukul 20.00) https://lasealwin.com/2017/08/24/ filosofiburung-dalam-sangkar-ketika-manusia-tidak-pernah-puas/ (diakses pada 27 September 2018, pukul 11.30) https://pengemishikmah. wordpress.com/2011/07/31/konsep-jiwadalam-pandangan-ibn-sina/ (diakses pada

21 Oktober 2018, pukul 13.20) https://www.pablopicasso.org/threemusicians.jsp (diakses pada 22 November 2018, pukul 20.00 